INTERNATIONAL BULLETIN OF BACTERIOLOGICAL NOMENCLATURE AND TAXONOMY

Volume 7 No. 3 July 15, 1957 pp. 143-145

\title{
NOMENCLATURAL REVIEW
}

Krassilnikov, N. A. Guide to the identification of the bacteria and Actinomycetes. (Section pertaining to Actinomycetes) Academy of Sciences, U.S.S.R. Moscow, 1949. Translation of section pertaining to Actinomycetes, edited by John B. Routien, Charles Pfizer and Co., Inc. 1957.

Dr. Routien and the Pfizer Company deserve the thanks of bacteriologists generally for this "offset" translation of the text on the Actinomycetes from Krassilnikov's original Russian.

Krassilnikov divides the Protophyta of Sachs into two groups:

I. Schizophyceae. These are organisms which form chlorophyll, phycocyanin, and phycoerythrin; they photosynthesize organic substances and liberate oxygen upon assimilation of carbon dioxide.

II. Schizomyceae. Nonchlorophyll-bearing organisms which contain neither phycocyanin nor phycoerythrin; they are colorless or colored but the pigments do not have photosynthetic properties; a basic majority of them are heterotrophic. Four classes are recognized:

1. Class Actinomycetes.

2. Class Eubacteriae.

3. Class Myxobacteriae.

4. Class Spirochaetae.

He also recognizes, in a supplement, an Order Chlamydozoa to include organisms which do not have a precise systematic position. He defines this order as "extreme minute or ultramicroscopic organisms, not visible with the ordinary optical microscope; they appear in the form of elementary corpuscles only after treatment by special methods. Rigid cytotropes inhabit the living cells. Their nature has not yet been studied. It is not known whether they are representative of bacteria, actinomycetes, fungi or protozoa." 
Page 144

I $N$ T ER A I I O N A L B ULLETIN

The Class Actinomycetes, Krassilnikov, 1945 is subdivided into three orders:

1. Order Actinomycetales. Organisms with a well-developed mycelium. On the branches of the mycelium there is formation of organs of fertility, i.e. spores.

2. Order Mycobacteriales. Bacillary, Gram-positive cells; well-developed branching in the typical forms; in the process of development, the cells are transformed into coccoid forms. In the degenerated coccoid forms (mycococci), lateral protuberances, which are the rudiments of branches, may be observed.

3. Order Coccaceae. Typical coccoid organisms without any protuberances whatever.

The Order Actinomycetales is divided into two families:

1. Family Actinomycetaceae. Well-defined mycelium or promycelium. The typical examples have multiple spores distributed in chains on the aerial branches of the mycelium.

2. Family Micromonosporaceae. Single spores, attached individually on the branches of the mycelium.

The Family Actinomycetaceae includes two genera:

1. Genus Actinomyces. Cultures with a well-developed, nonseptate mycelium.

2. Genus Proactinomyces. The cultures form a mycelium which is septate and readily fragments into bacilli and coci.

A key is given for identifying the 53 species of the genus Actinomyces. There is also a key for the differentiation of the 19 varieties of the species A. albus recognized, and for the 13 varieties of $\underline{A}$. flavus.

The reader is subjected to some nomenclatural confusion by the fact that in genus Actinomyces four species are recognized with illegitimate specific epithets; namely, A. viola- 
B A C T ER I OLOG I C A L NOME N C L A T URE $A N D \quad T A X O N O M Y$

ceus niger, A. longisporus ruber, A. longisporus flavus, and A. reticulus ruber. These epithets are illegitimate because there is lack of conformity with the binomial system of nomenclature for species. The species $\mathrm{A}$. micetomae might better have been transliterated from the Greek as mycetomatis.

The reader may also be confused by the fact that rather consistently Krassilnikov uses binomials in the naming of subspecies, particularly in those cases in which the species of other authors are reduced to subspecific rank.

The genus Proactinomyces includes 33 species with a key.

The family Micromonosporaceae includes the single genus Micromonospora with 9 species appearing in the key. 
